\title{
Associations of pineal volume, chronotype and symptom severity in adults with attention deficit hyperactivity disorder and healthy controls
}

\author{
Jan Malte Bumb ${ }^{a, *}$, Daniela Mier ${ }^{b}$, Ingo Noelte ${ }^{c}$, Michael Schredl $^{a}$, \\ Peter Kirsch $^{b}$, Oliver Hennig ${ }^{a}$, Luisa Liebrich ${ }^{e}$, Sabrina Fenske ${ }^{b}$, \\ Barbara Alm ${ }^{a}$, Carina Sauer ${ }^{b}$, Franz Markus Leweke ${ }^{a}$, \\ Esther Sobanski ${ }^{a, d}$
}

\author{
${ }^{a}$ Department of Psychiatry and Psychotherapy, Central Institute of Mental Health, \\ Medical Faculty Mannheim, Heidelberg University, Mannheim, Germany \\ ${ }^{\mathrm{b}}$ Department of Clinical Psychology, Central Institute of Mental Health, Medical Faculty Mannheim, \\ University of Heidelberg, Germany \\ 'Department of Neuroradiology, University Hospital Mannheim, Mannheim, Germany \\ ${ }^{\mathrm{d} D e p a r t m e n t}$ of Psychosomatic Medicine, Bad Dürkheim, Germany \\ 'Department of Internal Medicine, St. Claraspital, Basel, Switzerland
}

KEYWORDS

MPRAGE;

MRI;

Melatonin;

MEQ;

Morningness;

Eveningness

\begin{abstract}
The pineal gland, as part of the human epithalamus, is the main production site of peripheral melatonin, which promotes the modulation of sleep patterns, circadian rhythms and circadian preferences (morningness vs. eveningness). The present study analyses the pineal gland volume (PGV) and its association with circadian preferences and symptom severity in adult ADHD patients compared to healthy controls. PGV was determined manually using high-resolution 3 T MRI (T1magnetization prepared rapid gradient echo) in medication free adult ADHD patients $(N=74)$ compared to healthy controls $(N=86)$. Moreover, the Morningness-Eveningness Questionnaire (MEQ), the ADHD Diagnostic Checklist and the Wender-Utah Rating Scale were conducted. PGV differed between both groups (patients: $59.9 \pm 33.8 \mathrm{~mm}^{3}$; healthy controls: $71.4 \pm 27.2 \mathrm{~mm}^{3}$, $P=0.04$ ). In $A D H D$ patients, more eveningness types were revealed (patients: $29 \%$; healthy controls: $17 \% ; P=0.05$ ) and sum scores of the MEQ were lower (patients: $45.8 \pm 11.5$; healthy controls $67.2 \pm 10.1 ; P<0.001)$. Multiple regression analyses indicated a positive correlation of PGV and MEQ scores in ADHD $(\beta=0.856, P=0.003)$ but not in healthy controls $(\beta=0.054$,
\end{abstract}

*Correspondence to: Central Institute of Mental Health, Medical Faculty Mannheim, Heidelberg University J5, 68159, Mannheim, Germany. Tel.: +496211703 6161; fax: +496211703 2322 .

E-mail address: jan.bumb@zi-mannheim.de (J.M. Bumb). 
$P=0.688)$. Patients' MEQ scores $(\beta=-0.473, P=0.003)$ were negatively correlated to ADHD symptoms. The present results suggest a linkage between the PGV and circadian preference in adults with ADHD and an association of the circadian preference to symptom severity. This may facilitate the development of new chronobiological treatment approaches for the add-on treatment in ADHD.

\section{Introduction}

According to recent meta-analyses, the pooled prevalence of attention deficit hyperactivity disorder (ADHD) is $5.29 \%$ (Polanczyk et al., 2014). The disorder may be present in both children and adults, and is characterized by a vast spectrum of attentional deficits and behavioral difficulties, such as hyperactivity and impulsivity. While the burden of this disease is very high, its etiology is still not fully understood. It has been stated that complex and heterogeneous interferences of genetic and environmental factors contribute to its pathophysiology (Banaschewski et al., 2010; Faraone et al., 2005). Among these, altered sleep processes have been repeatedly associated to both, the pathogenesis as well as the course of ADHD (for review see (Yoon et al., 2012)). Studies have reported that $55 \%$ of children (Konofal et al., 2010) and 60$80 \%$ of adults (Sobanski et al., 2008) with ADHD suffer from altered sleep, such as sleep onset problems, restless and nonrestorative sleep, and increased daytime sleepiness (Schredl et al., 2007; Sobanski et al., 2014, 2008). Polysomnography and actigraphy studies also revealed reduced sleep efficiency, longer sleep onset latencies, increased nocturnal activity and more nocturnal awakenings in adult $\mathrm{ADHD}$ patients as compared to healthy controls (Kooij et al., 2001; Philipsen et al., 2005; Sobanski et al., 2008). Recently, it has also been demonstrated that there is a genetic overlap between clock genes and ADHD. In a sophisticated study Baird et al. (2012) stated that the expression of the clock genes BMAL1 and PER2 was significantly altered in ADHD. Recent investigations also examined the chronotypes of ADHD patients (Kooij and Bijlenga, 2013; Rybak et al., 2007; Van Veen et al., 2010; Voinescu et al., 2012). The chronotype refers to an attribute of individuals, reflecting at what time of the day they are most alert and active, and/or at what time they preferentially go to bed. There is a wide spectrum of chronotypes ranging from high morningness to high eveningness types (for review see (Imeraj et al., 2012)). The results suggest that ADHD patients might be characterized by a circadian preference toward eveningness (Baird et al., 2012; Rybak et al., 2007). Eveningness has been also associated to subsyndromal psychiatric symptoms in students (Sheaves et al., 2016) and it has been shown that eveningness chronotypes are more vulnerable for a chronic form of jet lag accompanied with sleep disturbances, vulnerability to depression and higher consumption of nicotine and alcohol (Rosenberg et al., 2014). Further, studies showed significant interactions between the chronotype and sleep efficiency (quality and quantity), which was poorer in evening types (Lehnkering and Siegmund, 2007; Vitale et al., 2015).

In general, chronotypes are mediated by the circadian system, which drives sleep/wake cycles in humans. The systems' master clock is in the suprachiasmatic nucleus of the hypothalamus. The suprachiasmatic nucleus receives afferent information via retinal photic input and conducts circadian rhythms via efferent signaling to the pineal gland (Baird et al., 2012). The pineal gland represents the main production site of peripheral melatonin, a versatile hormone participating in the promotion of circadian rhythms and sleep-onset times (Arendt and Skene, 2005). Alterations in the described pathways, e.g. disturbed pineal gland volume (PGV) and melatonin rhythm might thus lead to poor and disturbed sleep (Bumb et al., 2014; Riemann et al., 2002). So far, the only evidence for a link between PGV and chronotype is related to animal studies, demonstrating that nocturnal animals such as owls are characterized by very small and diurnal animals, e.g. horses by bigger pineal glands (for review see (Ralph, 1975)). Otherwise, it has been shown that the melatonin rhythm is related to circadian typology (for review see (Adan et al., 2012)). The acrophase, referring to the time at which the peak of a rhythm occurs, and the offset of human melatonin profiles in blood and saliva samples occur approximately three hours earlier in morningness types if compared to eveningness types (Gibertini et al., 1999; Griefahn et al., 2002; Mongrain et al., 2005, 2004). Moreover, it has been stated that morningness-eveningness questionnaire scores are inversely related to the time of the melatonin peak (Liu et al., 2000).

In addition, it has been suggested that alterations of the human PGV might be associated with psychiatric (schizophrenia and affective disorders) (Bersani et al., 2002; Findikli et al., 2015; Sarrazin et al., 2011) and other diseases, e.g. insomnia (Bumb et al., 2014). Moreover, disturbed sleep is known to induce or exacerbate ADHD symptoms (e.g. sleep deprivation is often accompanied by inattention, impulsivity and restlessness, frequently even in healthy controls) (Yoon et al., 2012), whereas good sleep hygiene and restorative sleep might alleviate attention and concentration in ADHD patients (Yoon et al., 2012). 'Alterations' of circadian rhythms and preferences might cause substantial difficulties and serious problems for e.g. employees or students with ADHD participating in the usual 9-to-5 day. Thus, treatment of disturbed sleep might significantly contribute to daytime functioning in patients with ADHD.

To get first insight into possible alterations of the neuroanatomy of the pineal gland in ADHD, we provide comparative volumetric analyses of the pineal gland in adult patients with ADHD and healthy controls. Moreover, we present the analyses of potential associations of both PGV and chronotype with ADHD symptom severity. 


\section{Experimental procedures}

The local ethics committee approved the study and written informed consent was obtained from all participants prior to enrollment in the study.

Data was assessed within a study evaluating medication effects in adult ADHD patients (publication ongoing) and healthy controls were recruited from the community via a newspaper advertisement. The data included in the current analyses were derived from the data collected prior to initiation of pharmacological treatment. Patients with ADHD were recruited at the Adult ADHD Outpatient Clinic at the Central Institute of Mental Health (CIMH), Mannheim, Germany.

The final sample consisted of 160 subjects (74 patients and 86 healthy controls). ADHD patients underwent a standardized clinical and diagnostic procedure according to German guidelines (Ebert et al., 2003). In the ADHD sample comorbidities, such as substance abuse, were also documented. 20 of the 74 ADHD patients had a positive history of psychiatric medication, including methylphenidate, atomoxetine, venlafaxine, citalopram, escitalopram, sertraline, mirtazapine, reboxetine, amitriptyline, trimipramine, bupropion, duloxetine, and haloperidol. For further details please see Table 2.

For inclusion, all participants had to be $18-55$ years old. Patients fulfilled pertinent criteria for ADHD according to DSM-IV-TR criteria and according to expert consensus (ES, BA, $\mathrm{OH}$ ). To be included, patients had to be rated with (i) $\geq 15$ points in the ADHD-Diagnostic Checklist (Rosler et al., 2004), (ii) $\geq 30$ points in the validated German Wender-Utah Rating Scale, Short Version (Retz-Junginger et al., 2003) and (iii) an IQ $>85$ (obtained by the Multiple Choice Vocabulary Test) to exclude psychosocial impairment due to reduced intelligence level. Exclusion criteria for healthy controls were any family history or current diagnosis of psychiatric (including anxiety disorders), neurological, neoplastic, or untreated endocrine disorders (other than nicotine addiction). Exclusion criteria for all participants were the intake of any medication, including methylphenidate, within 4 weeks before the start of the study, any unstable psychiatric and medical condition, current substance or alcohol abuse, as well as more than 10 points in the Beck Depression Scale. Individuals with contraindications to fMRI scanning were also excluded.

\subsection{MRI protocol}

MRI scans were performed using two 3 T MR scanners (MAGNETOM Trio, Siemens, Erlangen, Germany). Patients were scanned with a T1weighted, 3-dimensional magnetization prepared rapid acquisition gradient echo data set (MPRAGE) consisting of 192 sagittal sections (section thickness, $1 \mathrm{~mm}$; voxel size, $1 \times 1 \times 1 \mathrm{~mm}^{3}$; field of view, $256 \times 256 \mathrm{~mm}^{2}$; repetition time, $2300 \mathrm{~ms}$; echo time, $3.03 \mathrm{~ms}$; inversion time, $900 \mathrm{~ms}$; flip angle, $\left.9^{\circ}\right)$. Healthy controls were scanned with a T1-weighted, 3-dimensional magnetization prepared rapid acquisition gradient echo data set (MPRAGE) consisting of 192 sagittal sections (section thickness, $0.6 \mathrm{~mm}$; voxel size, $1 \times 1 \times 1 \mathrm{~mm}^{3}$; field of view, $217 \times 258 \mathrm{~mm}^{2}$; repetition time, $14 \mathrm{~ms}$; echo time, $4.92 \mathrm{~ms}$; flip angle, $25^{\circ}$ ). In a first step we analyzed the original datasets. To rule out that the different slice thicknesses might have influenced the results we reformatted 40 datasets with a slice thickness of 0.6-1 mm and conducted an inter slice thickness correlation analyses. Inter slice thickness reliability was satisfying $\left(r_{\mathrm{S}}=0.808 ; P<0.01\right.$, Spearman test).

All MR images were checked for artifacts affecting the image interpretation (movement artifacts, flow artifacts, etc.) by an experienced neuroradiologist (IN). All images were evaluated digitally using OsiriX software (www.osirix-viewer.com). PGV was mea sured blinded to diagnose, by manually defining the pineal borders on transversal reconstructed sequences. Further details concerning the evaluation of the PGV are given in (Bumb et al., 2014). We assessed both the intrarater variability (second analyses after 3 months) (JMB) and the interrater variability (a second evaluator $(I N)$, unaware of the results of the first evaluation, assessed ten randomly chosen datasets). All images were fully utilizable, none of the images had to be excluded because of impaired image quality. Both intrarater reliability $\left(r_{\mathrm{S}}=0.955 ; P<0.001\right.$, Spearman test) and interrater relia bility were high $\left(r_{\mathrm{S}}=0.952 ; P<0.001\right.$, Spearman test).

\subsection{Assessments}

\subsubsection{Morningness-Eveningness Questionnaire (MEQ)}

We used the validated German version (Griefahn et al., 2001) of the Morningness-Eveningness Questionnaire (D-MEQ; (Horne and Ostberg, 1976)). The MEQ is a self-rated instrument, consisting of 19 items to assess the chronobiological preferences of an individual. The MEQ sum scores may range between 13 and 86 . High sum scores (59-86) are associated to morningness, while lower scores point to eveningness (16-41) and intermediate scores (42-58) characterize the intermediate type (Horne and Ostberg, 1976). It is the most widely used scale to measure circadian typology (Caci et al., 2009b). In terms of reliability the MEQ consistently report high levels of reliability (>0.80) (Di Milia et al., 2013).

\subsubsection{ADHD diagnostic checklist (ADHD-DC)}

The ADHD-DC comprises 18 observer-rated items and assesses ageadapted ADHD symptoms according to DSM-IV and ICD-10 (International Classification of Diseases) research criteria. The diagnostic cutoff score is 15 points (range from $0-54$ ) and provides a sensitivity of $77 \%$ and a specificity of $75 \%$ (Rosler et al., 2004).

\subsection{Wender-Utah Rating Scale, Short Version (WURS-k)}

The validated German version of the WURS-k is a 25 -item self-rated instrument that assesses childhood ADHD symptoms retrospectively. The cutoff score is 30 points (range from 0 to 100) and provides a sensitivity of $85 \%$ and a specificity of $76 \%$ (Retz-Junginger et al., 2003).

\subsubsection{Multiple Choice Vocabulary Test (MWT-B)}

The MWT-B (Lehrl, 1997) is an instrument widely used in Germany to assess the verbal IQ, which has been shown to correlate highly (correlation coefficient 0.81 ) to other well-established instruments to measure intelligence, such as the Hamburg-Wechsler-Intelligence test for adults (HAWIE) (Wiessner and Felber, 1981).

\subsection{Statistics}

Statistical analyses were performed using SPSS 20 (IBM Corp., Armonk, NY, USA) for Macintosh. Sociodemographic characteristics were compared using 2-sample $t$-test. Volumes, as well as chronotype differences were assessed using an ANCOVA, considering gender and age as a covariate. Since these two factors have been discussed controversially to be associated with both PGV (Bumb et al., 2012, 2013; Hasegawa et al., 1987; Schmitz et al., 2006) as well as preference for morningness or eveningness (Bae et al., 2010), we decided to integrate them as covariates in our analyses.

Intra- and interrater, as well as inter slice thickness reliability were determined by Spearman rank correlation. We conducted stratified analyses on diagnose and multiple regression analysis was applied for the analysis of PGV and MEQ score within groups. Age, gender, ADHD diagnostic checklist and WURS-k sum scores, as well as ADHD subtype (inattentive vs. combined type) were considered as predictors. 


\section{Results}

We performed a post-hoc power analysis, using G*Power (Faul et al., 2007) that revealed a statistical power of 0.71 (ANCOVA) and 0.83 (multiple regression) respectively to detect a medium effect $(d=0.3)$. Sociodemographic data and further sample characteristics (MEQ, ADHD-DC and WURS-k scores) are given in Tables 1 and 2.

\subsection{Associations of pineal gland volume, MEQ and ADHD symptom scores}

PGV ranged from 10.9 to $189.3 \mathrm{~mm}^{3}$ (mean $59.9 \pm 33.8 \mathrm{~mm}^{3}$ ) in $A D H D$ patients and from 0.53 to $175.2 \mathrm{~mm}^{3}$ (mean $71.4 \pm 27.2 \mathrm{~mm}^{3}$ ) in healthy controls. PGV differed in ADHD patients and healthy controls $(F=4.282, P=0.04$; ANCOVA) (Figure 1). PGV in the whole sample was not associated with both age $(F=0.442, P=0.507$; ANCOVA $)$ and sex $(F=2.7$, $P=0.102$; ANCOVA). $P G V$ in patients was associated to the MEQ score $(F=5.061 P=0.034$; ANCOVA).

To rule out a relevant effect of age on the group difference of the PGV, we further analyzed a subsample $(N=57$; ADHD patients $N=29$; healthy controls $N=28$ ), which was matched according to age (ADHD patients: range from 20 to 28 years; mean age was $25.2 \pm 2.4$ years; healthy controls: range from 24 to 28 years; mean age was $25.5 \pm 1.2$ years; $P=0.353$; Mann Whitney test) and gender (ADHD patients vs. healthy controls (f/m): $10 / 19$ vs. $14 / 14 ; P=0.292 ;$ Mann Whitney test). In this subsample, PGV differed significantly between groups (ADHD patients: $60.82 \pm 37.79 \mathrm{~mm}^{3}$ and healthy controls: $75.63 \pm 25.47 \mathrm{~mm}^{3} ; P=0.007$; Mann Whitney test).

MEQ scores were only available in $57 \%$ of all subjects ( $31 /$ 74 patients) and (60/86 healthy controls)). MEQ scores and chronotype differed between patients and healthy controls (MEQ scores: $F=13.640, P<0.001$; chronotype: $F=3.891$, $P=0.05$, respectively; ANCOVA) (Figure 1). In detail, more eveningness types were revealed in the patient group than in the control group ( $29 \%$ vs. $16 \%)$.

Multiple regression analyses revealed a positive correlation of PGV and MEQ scores in patients $\left(\beta=0.856, r_{\mathrm{S}}=0.621\right.$, $P=0.003)$ but not in healthy controls $\left(\beta=0.054, r_{\mathrm{S}}=0.054\right.$, $P=0.688)$. The correlation coefficients differed significantly $(P=0.006)$. Moreover, patients' MEQ scores were correlated to age $\left(\beta=0.609, r_{\mathrm{S}}=0.670, P<0.001\right)$ and inversely to ADHD-DC scores $\left(\beta=-0.473, \quad r_{\mathrm{S}}=-0.586, \quad P=0.003\right)$ (Figure 2). The analyses did not reveal significant correlations between any of the reported parameters and the WURS-k scores $\left(P_{\min }=0.159\right)$.

\section{Discussion}

Our study is the first to show that PGV, measured by highresolution $M R I$ sequences, is significantly smaller in unmedicated $\mathrm{ADHD}$ patients than in healthy controls. Moreover, $\mathrm{ADHD}$ patients had lower MEQ scores than healthy controls, indicating a preference towards eveningness in patients, and MEQ scores were positively related to $\mathrm{PGV}$ in $\mathrm{ADHD}$, but not in healthy controls.

In 2011 the Grand Challenges in Global Mental Health Initiative (GCMHI) defined clarifying the causes of ADHD, improving diagnosis and treatment, developing preventive
Table 1 Sociodemographic characteristics of ADHD patients and healthy controls.

\begin{tabular}{|c|c|c|c|}
\hline & ADHD patients & $\begin{array}{l}\text { Healthy } \\
\text { controls }\end{array}$ & $P$ value \\
\hline $\operatorname{Sex}(f / m)$ & $\begin{array}{l}33(44.6 \%) / 41 \\
(55.4 \%)\end{array}$ & $\begin{array}{l}45(52.3 \%) / \\
41(48.7 \%)\end{array}$ & $0.349^{a}$ \\
\hline Age (years) & $32.7 \pm 8.1$ & $23.1 \pm 2.6$ & $<0.001^{a}$ \\
\hline PGV $\left[\mathrm{mm}^{3}\right]$ & $59.9 \pm 33.8$ & $71.4 \pm 27.2$ & $0.04^{b}$ \\
\hline MEQ score & $45.8 \pm 11.5$ & $67.2 \pm 10.1$ & $<0.001^{b}$ \\
\hline Chronotype & 31 & 60 & $0.05^{b}$ \\
\hline Morningness & $3(9.7 \%)$ & $20(33.3 \%)$ & \\
\hline Eveningness & $9(29.0 \%)$ & $10(16.7 \%)$ & \\
\hline Intermediate & 19 (61.3\%) & $30(50.0 \%)$ & \\
\hline $\begin{array}{l}\text { ADHD-DC } \\
\text { score }\end{array}$ & $29.7 \pm 7.2$ & - & \\
\hline WURS-k score & $40.5 \pm 15$ & - & \\
\hline ADHD sample & 74 & - & \\
\hline $\begin{array}{l}\text { Combined } \\
\text { subtype }\end{array}$ & $61(82 \%)$ & - & \\
\hline $\begin{array}{c}\text { Inattentive } \\
\text { subtype }\end{array}$ & $13(18 \%)$ & - & \\
\hline IQ & $\begin{array}{l}108.4 \pm 14.4 \\
\text { (range: } 86- \\
143 \text { ) }\end{array}$ & - & \\
\hline
\end{tabular}

Values are given as mean $\pm \mathrm{SD}$; significant $P$ values are highlighted in bold.

PGV Pineal gland volume

MEQ Morningness-Eveningness Questionnaire

ADHD-DC ADHD Diagnostic checklist

WURS-k Wender-Utah Rating Scale, Short Version

${ }^{a} 2$-sample $t$-test;

'ANCOVA with the factors 'diagnosis' (depicted), 'gender' and 'age' as covariates

Table 2 Comorbidities and medication history of the ADHD patients.

\begin{tabular}{ll}
\hline Comorbidity & $n / N$ \\
\hline No comorbidity & $50 / 74$ \\
History of psychiatric medication & $20 / 74$ \\
Substance abuse & $3 / 74$ \\
Social phobia & $3 / 74$ \\
Specific phobia & $3 / 74$ \\
Recurrent major depression & $2 / 74$ \\
Generalized anxiety disorder & $1 / 74$ \\
Gambling addiction & $1 / 74$ \\
Bulimia & $2 / 74$ \\
Adjustment disorder & $1 / 74$ \\
Dyslexia & $2 / 74$ \\
'Other' & $6 / 74$ \\
\hline
\end{tabular}

strategies and defining the global burden of disease as one out of 25 'urgent research topics' (Collins et al., 2011). Along with functional changes, it has been shown, that ADHD is associated with a $3-5 \%$ smaller total brain size, attributed to a reduced gray matter compared to controls (Castellanos et al., 2002; Durston et al., 2004; Greven 
et al., 2015). Moreover, total brain volume correlates negatively with $A D H D$ symptoms in the general population (Hoogman et al., 2012). Meta-analyses have detected smaller volumes across several brain regions, most consistently in the right globus pallidus, right putamen, caudate nucleus and cerebellum of ADHD patients if compared to healthy controls (Frodl and Skokauskas, 2012; Stoodley and Schmahmann, 2009). To the best of our knowledge, we are the first to show alterations of PGV in ADHD. In humans, the pineal gland arises out of the third ventricle, and it is fullygrown after the first years of life, instead of developing and adapting during adolescence and even later, as it is known for many other brain structures (Golan et al., 2002; Hasegawa et al., 1987; Schmidt et al., 1995; Sumida et al., 1996). Therefore, the described findings suggest a specific ADHD-related mechanism that impairs circadian control by the pineal gland, which may play a central role in circadian rhythms and chronobiological preferences in adult ADHD patients. The present findings are consistent with the results of animal studies (for review see (Ralph, 1975)), reporting smaller, almost 'atrophic', pineal glands in nocturnal animals such as owls, and bigger pineal glands in diurnal animals, e.g. horses. More recent studies in humans have also linked reduced PGV to disorders associated with significant sleep disturbances, such as primary insomnia (Bumb et al., 2014) and schizophrenia (Bersani et al., 2002; Findikli et al., 2015). In line with this, other researchers have detected a link between PGV and the endocrine level by demonstrating that functional pineal parenchyma is correlated to melatonin serum levels (Kunz et al., 1999; Liebrich et al., 2014; Nolte et al., 2009). Furthermore, the degree of pineal calcification has been linked to the behavioral level, since it correlates negatively with total sleep time and sleep efficiency in insomnia patients (Mahlberg et al., 2009).

There is emerging evidence that ADHD patients are characterized by a circadian preference toward eveningness (Baird et al., 2012; Rybak et al., 2007). In the present sample, MEQ scores were significantly lower in ADHD patients, and evening types were more frequent in $A D H D$ compared to healthy controls $(29 \%$ vs. $16 \%)$. In the general population, the prevalence of evening types ranges between $2 \%$ and $29 \%$, strongly depending on the age and instrument used to measure the chronotype (Kooij and Bijlenga, 2013). In this context it has been shown, that children and older people are characterized by earlier chronotypes, while young adults reach a peak of 'eveningness' at the age of approximately 20 years (Roenneberg et al., 2007). In the present sample the mean age of healthy controls was 23.1 years and of ADHD patients 32.7 years. Nevertheless, evening types were more frequent in ADHD patients, underlining the described association of ADHD and preference for eveningness. Our findings are consistent with other studies reporting that ADHD patients show a preference towards eveningness (Bae et al., 2010; Bijlenga et al., 2013; Caci et al., 2009a; Rybak et al., 2007; Van Veen et al., 2010; Voinescu et al., 2012).

Regression analyses revealed a significant correlation between a preference for eveningness (low MEQ score) and symptom severity, as measured by the ADHD-DC in patients. It has been shown that disturbed sleep might worsen ADHD symptoms, while restorative sleep might alleviate attention and concentration in patients (Yoon et al., 2012). The present findings are in line with a growing body of research supporting the importance of altered circadian rhythms and associated pathways in ADHD (Baird et al., 2012; Yoon et al., 2012). Baird et al. (2012) suggested that ADHD is associated with alterations in circadian rhythms at the behavioral level (e.g. delayed sleep onset, disturbed awakenings, increased nocturnal activity, reduced sleep efficiency and less Rapid Eye Movement (REM) sleep), endocrine level (e.g. melatonin and cortisol) and molecular level (e.g. positive and negative transcriptional/translational feedback loops of 'clock' genes and their protein products, and single-nucleotide polymorphism in clock genes). To conclude, the findings of this study are consistent a

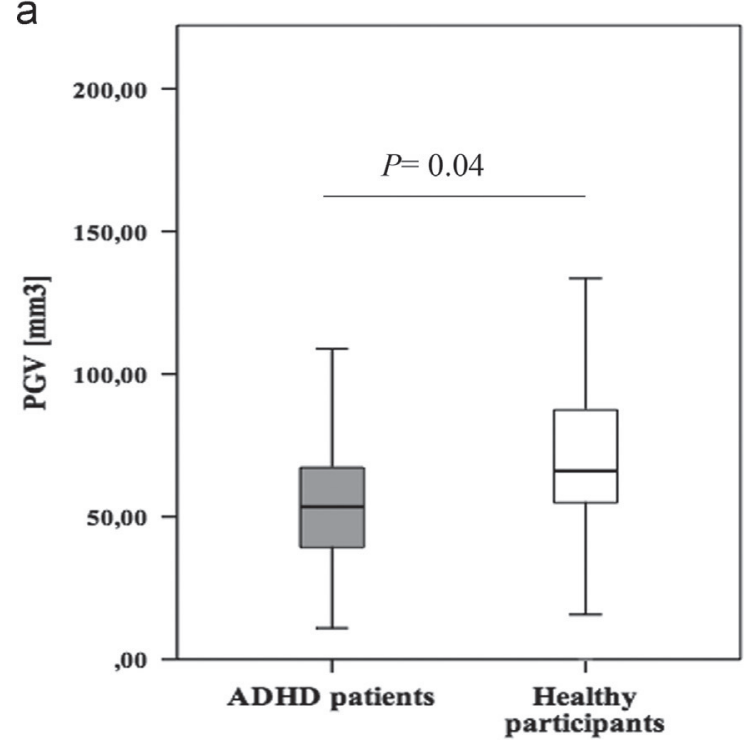

b

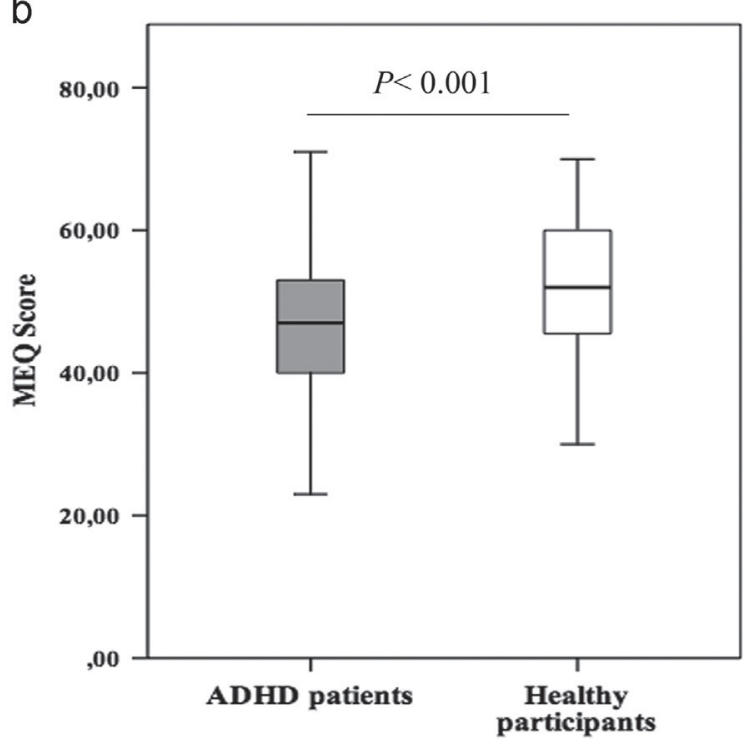

Figure 1 Box-and-whiskers plots (box shows 5 and 95 percentiles and mean value) of (a) pineal gland volume (PGV) in ADHD patients compared to healthy controls and of (b) Morningness-Eveningness Questionnaire scores (MEQ scores) in both groups. 
a

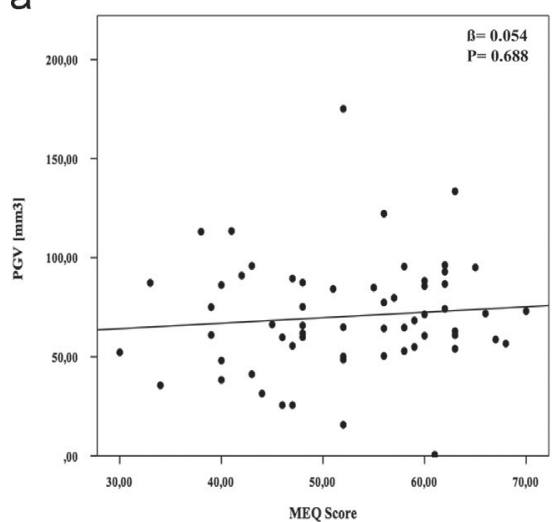

b

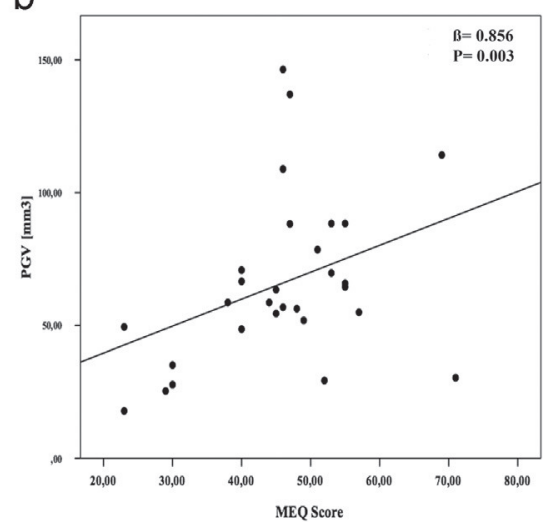

C

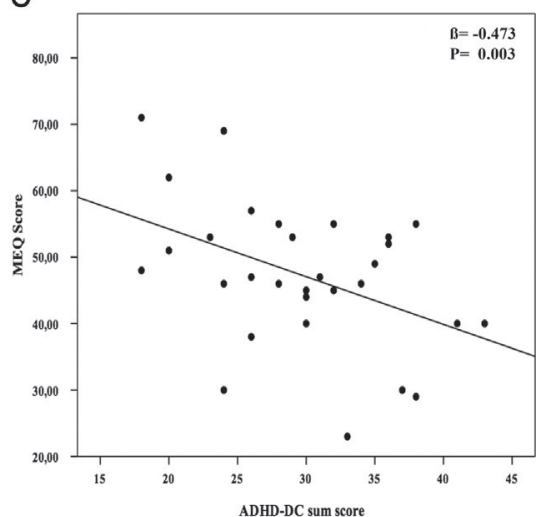

Figure 2 Spearman's correlation analyses of pineal gland volume (PGV) and Morningness-Eveningness Questionnaire score (MEQ score) in (a) healthy controls and (b) ADHD patients and of (c) MEQ score and ADHD Diagnostic checklist (ADHD-DC) score in patients.

with the present results since ADHD patients showed a preference towards eveningness, i.e. low MEQ scores, which again were negatively correlated to symptom severity.

A limitation of the present study is that we did not conduct additional CT scans or further MRI sequences, and we are therefore not able to elucidate to what extent the potential role of pineal calcifications may have influenced the results. Moreover, we did not measure melatonin plasma levels, and any potential associations between PGV, melatonin levels and their implications for chronotypology and ADHD symptoms can only be hypothesized. Also, it cannot be ruled out that lower PGV is connected to delayed circadian rhythm in general regardless of the presence of ADHD. In addition, the present study cannot resolve the degree to which the different slice thicknesses or agedependent processes might have influenced the results. However, both the subanalysis performed in an age and gender matched subsample also revealed a significant difference of the PGV between both groups and the interslice thickness reliability was very high. The lack of ADHD ratings in the control sample may be a limitation, as well. Apart from the fact that not all of the neuropsychiatric assessments were performed at the same time of the day, also the fact that only $57 \%$ of the participants completed the MEQ may have impacted the results. Finally, because of the small sample size the described results needs replication in bigger samples.

As yet, the underlying mechanisms of circadian rhythm alterations in psychiatric disorders are still not fully understood, and a growing body of research is culminating with regards to this topic. A recent systematic review (Imeraj et al., 2012) summarized data on ADHD fluctuations across the day in terms of morningness-eveningness chronotypology, time of day effects of behavior and activity and both sleep-wake rhythm problems and rhythmicity in neuroendocrine and neurophysiological factors. On the basis of our findings, we suggest that alterations of the PGV and associated variations in the absolute melatonin levels as well as circadian melatonin rhythms may influence the etiology and the course of ADHD. We have further demonstrated associations between the PGV and chronotypology, and provided a link between MEQ scores and symptom severity in ADHD. Bearing in mind the clinical implications associated with these findings, we suggest that the results presented here may encourage the development of new chronobiological treatments for the (add-on) treatment of $A D H D$. Regarding this, it has been reported that children suffering from ADHD and comorbid insomnia may benefit from exogenous melatonin administration (Imeraj et al., 2012). While light therapy might exert beneficial effects in adults with ADHD and comorbid delayed sleep phase (Rybak et al., 2007), studies investigating melatonin administration in adult ADHD are still lacking (Imeraj et al., 2012). However, ADHD patients, often do not prefer the morning hours, are most alert and active in the late afternoon and the evening hours, which is associated with substantial difficulties with well-established social standards, such as educational concepts, national curricula and the regulation of working hours and/or work shifts at present. As regards the chronotypology, the evaluation of currently state-ofthe-art dosing and timing of ADHD medication could also be re-considered. The explicit examination of sleep problems in ADHD might reveal subgroups, which again may improve the dissatisfying treatment response and remission rates.

\section{Financial disclosures}

Esther Sobanski is advisor for Eli Lilly, Shire und Medice and was involved in studies for Eli Lilly, Janssen and Medice. Barbara Alm has received speaker's fees from Novartis and Lilly, was on advisory boards for Lilly and was involved in phase III-studies by Lilly and Novartis. Oliver Hennig has received speaker's fees from Lilly and Medice and was involved in studies for Lilly. Michael Schredl has received financial support from MSD Sharp \& Dohme GmbH (pharmaceutical company). The other authors declare no conflict of interests.

\section{Contributors}

$E S, D M, M S$, and JMB contributed to the conception and design of the study. JMB, LL, OH, BA, SF, CS and ES performed the experiments. ES, JMB, DM, MS, PK and FML analyzed the data. JMB, ES and DM wrote the first draft of the manuscript. JMB, ES, MS, PK, IN and $F M L$ contributed to interpretation of findings. JMB, ES, PK and FML 
drafted the article, which was revised critically and approved for publication by all authors.

\section{Conflict of interest}

The other authors declare no conflict of interests.

\section{Acknowledgments}

We thank Ms. Schmid for editing this article.

\section{References}

Adan, A., Archer, S.N., Hidalgo, M.P., Di Milia, L., Natale, V., Randler, C., 2012. Circadian typology: a comprehensive review. Chronobiol. Int. 29, 1153-1175.

Arendt, J., Skene, D.J., 2005. Melatonin as a chronobiotic. Sleep Med. Rev. 9, 25-39.

Bae, S.M., Park, J.E., Lee, Y.J., Cho, I.H., Kim, J.H., Koh, S.H., Kim, S.J., Cho, S.J., 2010. Gender difference in the association between adult attention deficit hyperactivity disorder symptoms and morningness-eveningness. Psychiatry Clin. Neurosci. 64, 649-651.

Baird, A.L., Coogan, A.N., Siddiqui, A., Donev, R.M., Thome, J., 2012. Adult attention-deficit hyperactivity disorder is associated with alterations in circadian rhythms at the behavioural, endocrine and molecular levels. Mol. Psychiatry 17, 988-995.

Banaschewski, T., Becker, K., Scherag, S., Franke, B., Coghill, D., 2010. Molecular genetics of attention-deficit/hyperactivity disorder: an overview. Eur. Child. Adolesc. Psychiatry 19, 237-257.

Bersani, G., Garavini, A., lannitelli, A., Quartini, A., Nordio, M., Di Biasi, C., Pancheri, P., 2002. Reduced pineal volume in male patients with schizophrenia: no relationship to clinical features of the illness. Neurosci. Lett. 329, 246-248.

Bijlenga, D., Van Someren, E.J., Gruber, R., Bron, T.I., Kruithof, I. F., Spanbroek, E.C., Kooij, J.J., 2013. Body temperature, activity and melatonin profiles in adults with attention-deficit/ hyperactivity disorder and delayed sleep: a case-control study. J. Sleep Res. 22, 607-616.

Bumb, J.M., Brockmann, M.A., Groden, C., Al-Zghloul, M., Nolte, I., 2012. TrueFISP of the pediatric pineal gland: volumetric and microstructural analysis. Clin. Neuroradiol. 22, 69-77.

Bumb, J.M., Brockmann, M.A., Groden, C., Nolte, I., 2013. Microstructural analysis of pineal volume using trueFISP imaging. World J. Radiol. 5, 166-172.

Bumb, J.M., Schilling, C., Enning, F., Haddad, L., Paul, F., Lederbogen, F., Deuschle, M., Schredl, M., Nolte, I., 2014. Pineal gland volume in primary insomnia and healthy controls: a magnetic resonance imaging study. J. Sleep Res. 23, 274-280.

Caci, H., Bouchez, J., Bayle, F.J., 2009a. Inattentive symptoms of ADHD are related to evening orientation. J. Atten. Disord. 13, 36-41.

Caci, H., Deschaux, O., Adan, A., Natale, V., 2009b. Comparing three morningness scales: age and gender effects, structure and cut-off criteria. Sleep Med. 10, 240-245.

Castellanos, F.X., Lee, P.P., Sharp, W., Jeffries, N.O., Greenstein, D. K., Clasen, L.S., Blumenthal, J.D., James, R.S., Ebens, C.L., Walter, J.M., Zijdenbos, A., Evans, A.C., Giedd, J.N., Rapoport, J.L., 2002. Developmental trajectories of brain volume abnormalities in children and adolescents with attention-deficit/hyperactivity disorder. JAMA 288, 1740-1748.

Collins, P.Y., Patel, V., Joestl, S.S., March, D., Insel, T.R., Daar, A. S., Scientific Advisory, B., the Executive Committee of the Grand Challenges on Global Mental, H., Anderson, W., Dhansay, M.A., Phillips, A., Shurin, S., Walport, M., Ewart, W., Savill, S.J., Bordin, I.A., Costello, E.J., Durkin, M., Fairburn, C., Glass, R.I.,
Hall, A., Huang, Y., Hyman, S.E., Jamison, K., Kaaya, S., Kapur, S., Kleinman, A., Ogunniyi, A., Otero-Ojeda, A., Poo, M.M., Ravindranath, V., Sahakian, B.J., Saxena, S., Singer, P.A., Stein, D.J., 2011. Grand challenges in global mental health. Nature 475, 27-30.

Di Milia, L., Adan, A., Natale, V., Randler, C., 2013. Reviewing the psychometric properties of contemporary circadian typology measures. Chronobiol. Int. 30, 1261-1271.

Durston, S., Hulshoff Pol, H.E., Schnack, H.G., Buitelaar, J.K., Steenhuis, M.P., Minderaa, R.B., Kahn, R.S., van Engeland, H., 2004. Magnetic resonance imaging of boys with attentiondeficit/hyperactivity disorder and their unaffected siblings. J. Am. Acad. Child. Adolesc. Psychiatry 43, 332-340.

Ebert, D., Krause, J., Roth-Sackenheim, C., 2003. ADHD in adulthood-guidelines based on expert consensus with DGPPN support. Nervenarzt 74, 939-946.

Faraone, S.V., Perlis, R.H., Doyle, A.E., Smoller, J.W., Goralnick, J. J., Holmgren, M.A., Sklar, P., 2005. Molecular genetics of attention-deficit/hyperactivity disorder. Biol. Psychiatry 57, 1313-1323.

Faul, F., Erdfelder, E., Lang, A.G., Buchner, A., 2007. G*Power 3: a flexible statistical power analysis program for the social, behavioral, and biomedical sciences. Behav. Res. Methods 39, 175-191.

Findikli, E., Inci, M.F., Gokce, M., Findikli, H.A., Altun, H., Karaaslan, M.F., 2015. Pineal gland volume in schizophrenia and mood disorders. Psychiatr. Danub. 27, 153-158.

Frodl, T., Skokauskas, N., 2012. Meta-analysis of structural MRI studies in children and adults with attention deficit hyperactivity disorder indicates treatment effects. Acta Psychiatr. Scand. $125,114-126$.

Gibertini, M., Graham, C., Cook, M.R., 1999. Self-report of circadian type reflects the phase of the melatonin rhythm. Biol. Psychol. 50, 19-33.

Golan, J., Torres, K., Staskiewicz, G.J., Opielak, G., Maciejewski, R., 2002. Morphometric parameters of the human pineal gland in relation to age, body weight and height. Folia Morphol. 61, 111-113.

Greven, C.U., Bralten, J., Mennes, M., O'Dwyer, L., van Hulzen, K. J., Rommelse, N., Schweren, L.J., Hoekstra, P.J., Hartman, C. A., Heslenfeld, D., Oosterlaan, J., Faraone, S.V., Franke, B., Zwiers, M.P., Arias-Vasquez, A., Buitelaar, J.K., 2015. Developmentally stable whole-brain volume reductions and developmentally sensitive caudate and putamen volume alterations in those with attention-deficit/hyperactivity disorder and their unaffected siblings. JAMA Psychiatry 72, 490-499.

Griefahn, B., Künemund, C., Bröde, P., Mehnert, P., 2001. The validity of a German version of the Morningness-EveningnessQuestionnaire developed by Horne and Östberg. Somnologie 5, 71-80.

Griefahn, B., Kunemund, C., Golka, K., Thier, R., Degen, G., 2002. Melatonin synthesis: a possible indicator of intolerance to shiftwork. Am. J. Ind. Med. 42, 427-436.

Hasegawa, A., Ohtsubo, K., Mori, W., 1987. Pineal gland in old age; quantitative and qualitative morphological study of 168 human autopsy cases. Brain Res. 409, 343-349.

Hoogman, M., Rijpkema, M., Janss, L., Brunner, H., Fernandez, G., Buitelaar, J., Franke, B., Arias-Vasquez, A., 2012. Current selfreported symptoms of attention deficit/hyperactivity disorder are associated with total brain volume in healthy adults. PLoS One 7, e31273.

Horne, J.A., Ostberg, O., 1976. A self-assessment questionnaire to determine morningness-eveningness in human circadian rhythms. Int. J. Chronobiol. 4, 97-110.

Imeraj, L., Sonuga-Barke, E., Antrop, I., Roeyers, H., Wiersema, R., Bal, S., Deboutte, D., 2012. Altered circadian profiles in attention-deficit/hyperactivity disorder: an integrative review 
and theoretical framework for future studies. Neurosci. Biobehav. Rev. 36, 1897-1919.

Konofal, E., Lecendreux, M., Cortese, S., 2010. Sleep and ADHD. Sleep Med. 11, 652-658.

Kooij, J.J., Bijlenga, D., 2013. The circadian rhythm in adult attention-deficit/hyperactivity disorder: current state of affairs. Expert Rev. Neurother. 13, 1107-1116.

Kooij, J.J., Middelkoop, H.A., van Gils, K., Buitelaar, J.K., 2001. The effect of stimulants on nocturnal motor activity and sleep quality in adults with ADHD: an open-label case-control study. J. Clin. Psychiatry 62, 952-956.

Kunz, D., Schmitz, S., Mahlberg, R., Mohr, A., Stoter, C., Wolf, K.J., Herrmann, W.M., 1999. A new concept for melatonin deficit: on pineal calcification and melatonin excretion. Neuropsychopharmacology 21, 765-772.

Lehnkering, H., Siegmund, R., 2007. Influence of chronotype, season, and sex of subject on sleep behavior of young adults. Chronobiol. Int. 24, 875-888.

Lehrl, S., 1997. Multiple Choice Vocabulary Test [German: Mehrfach-Wortschatz-Intelligenztest: Form B]. Dr. D. Straube, Erlangen, Germany.

Liebrich, L.S., Schredl, M., Findeisen, P., Groden, C., Bumb, J.M., Nolte, I.S., 2014. Morphology and function: MR pineal volume and melatonin level in human saliva are correlated. J. Magn. Reson. Imaging 40, 966-971.

Liu, X., Uchiyama, M., Shibui, K., Kim, K., Kudo, Y., Tagaya, H., Suzuki, H., Okawa, M., 2000. Diurnal preference, sleep habits, circadian sleep propensity and melatonin rhythm in healthy human subjects. Neurosci. Lett. 280, 199-202.

Mahlberg, R., Kienast, T., Hadel, S., Heidenreich, J.O., Schmitz, S., Kunz, D., 2009. Degree of pineal calcification (DOC) is associated with polysomnographic sleep measures in primary insomnia patients. Sleep Med. 10, 439-445.

Mongrain, V., Carrier, J., Dumont, M., 2005. Chronotype and sex effects on sleep architecture and quantitative sleep EEG in healthy young adults. Sleep 28, 819-827.

Mongrain, V., Lavoie, S., Selmaoui, B., Paquet, J., Dumont, M., 2004. Phase relationships between sleep-wake cycle and underlying circadian rhythms in morningness-eveningness. J. Biol. Rhythms 19, 248-257.

Nolte, I., Lutkhoff, A.T., Stuck, B.A., Lemmer, B., Schredl, M., Findeisen, P., Groden, C., 2009. Pineal volume and circadian melatonin profile in healthy volunteers: an interdisciplinary approach. J. Magn. Reson. Imaging 30, 499-505.

Philipsen, A., Feige, B., Hesslinger, B., Ebert, D., Carl, C., Hornyak, M., Lieb, K., Voderholzer, U., Riemann, D., 2005. Sleep in adults with attention-deficit/hyperactivity disorder: a controlled polysomnographic study including spectral analysis of the sleep EEG. Sleep 28, 877-884.

Polanczyk, G.V., Willcutt, E.G., Salum, G.A., Kieling, C., Rohde, L. A., 2014. ADHD prevalence estimates across three decades: an updated systematic review and meta-regression analysis. Int. J. Epidemiol. 43, 434-442.

Ralph, C.L., 1975. The pineal gland and geographical distribution of animals. Int. J. Biometeorol. 19, 289-303.

Retz-Junginger, P., Retz, W., Blocher, D., Stieglitz, R.D., Georg, T., Supprian, T., Wender, P.H., Rosler, M., 2003. Reliability and validity of the Wender-Utah-Rating-Scale short form. Retrospective assessment of symptoms for attention deficit/hyperactivity disorder. Nervenarzt 74, 987-993.

Riemann, D., Klein, T., Rodenbeck, A., Feige, B., Horny, A., Hummel, R., Weske, G., Al-Shajlawi, A., Voderholzer, U., 2002. Nocturnal cortisol and melatonin secretion in primary insomnia. Psychiatry Res. 113, 17-27.
Roenneberg, T., Kuehnle, T., Juda, M., Kantermann, T., Allebrandt, K., Gordijn, M., Merrow, M., 2007. Epidemiology of the human circadian clock. Sleep Med. Rev. 11, 429-438.

Rosenberg, J., Maximovll, J., Reske, M., Grinberg, F., Shah, N.J., 2014. "Early to bed, early to rise": diffusion tensor imaging identifies chronotype-specificity. Neuroimage 84, 428-434.

Rosler, M., Retz, W., Retz-Junginger, P., Thome, J., Supprian, T., Nissen, T., Stieglitz, R.D., Blocher, D., Hengesch, G., Trott, G. E., 2004. Tools for the diagnosis of attention-deficit/hyperactivity disorder in adults. Self-rating behaviour questionnaire and diagnostic checklist. Nervenarzt 75, 888-895.

Rybak, Y.E., McNeely, H.E., Mackenzie, B.E., Jain, U.R., Levitan, R. D., 2007. Seasonality and circadian preference in adult attention-deficit/hyperactivity disorder: clinical and neuropsychological correlates. Compr. Psychiatry 48, 562-571.

Sarrazin, S., Etain, B., Vederine, F.E., d'Albis, M.A., Hamdani, N., Daban, C., Delavest, M., Lepine, J.P., Leboyer, M., Mangin, J.F., Poupon, C., Houenou, J., 2011. MRI exploration of pineal volume in bipolar disorder. J. Affect. Disord. 135, 377-379.

Schmidt, F., Penka, B., Trauner, M., Reinsperger, L., Ranner, G., Ebner, F., Waldhauser, F., 1995. Lack of pineal growth during childhood. J. Clin. Endocrinol. Metab. 80, 1221-1225.

Schmitz, S.A., Platzek, I., Kunz, D., Mahlberg, R., Wolf, K.J., Heidenreich, J.O., 2006. Computed tomography of the human pineal gland for study of the sleep-wake rhythm: reproducibility of a semi-quantitative approach. Acta Radiol. 47, 865-871.

Schredl, M., Alm, B., Sobanski, E., 2007. Sleep quality in adult patients with attention deficit hyperactivity disorder (ADHD). Eur. Arch. Psychiatry Clin. Neurosci. 257, 164-168.

Sheaves, B., Porcheret, K., Tsanas, A., Espie, C.A., Foster, R.G., Freeman, D., Harrison, P.J., Wulff, K., Goodwin, G.M., 2016. Insomnia, nightmares, and chronotype as markers of risk for severe mental illness: results from a student population. Sleep 39, 173-181.

Sobanski, E., Alm, B., Hennig, O., Riemann, D., Feige, B., Schredl, M., 2014. Daytime sleepiness in adults with ADHD: a pilot trial with a multiple sleep latency test. J. Atten. Disord.

Sobanski, E., Schredl, M., Kettler, N., Alm, B., 2008. Sleep in adults with attention deficit hyperactivity disorder (ADHD) before and during treatment with methylphenidate: a controlled polysomnographic study. Sleep 31, 375-381.

Stoodley, C.J., Schmahmann, J.D., 2009. Functional topography in the human cerebellum: a meta-analysis of neuroimaging studies. Neuroimage 44, 489-501.

Sumida, M., Barkovich, A.J., Newton, T.H., 1996. Development of the pineal gland: measurement with MR. AJNR Am. J. Neuroradiol. 17, 233-236.

Van Veen, M.M., Kooij, J.J., Boonstra, A.M., Gordijn, M.C., Van Someren, E.J., 2010. Delayed circadian rhythm in adults with attention-deficit/hyperactivity disorder and chronic sleep-onset insomnia. Biol. Psychiatry 67, 1091-1096.

Vitale, J.A., Roveda, E., Montaruli, A., Galasso, L., Weydahl, A., Caumo, A., Carandente, F., 2015. Chronotype influences activity circadian rhythm and sleep: differences in sleep quality between weekdays and weekend. Chronobiol. Int. 32, 405-415.

Voinescu, B.I., Szentagotai, A., David, D., 2012. Sleep disturbance, circadian preference and symptoms of adult attention deficit hyperactivity disorder (ADHD). J. Neural Transm. 119, 1195-1204.

Wiessner, B., Felber, W., 1981. Agreement between 2 diagnostic intelligence test procedures (HAWIE and MWT-B) in a sample of patients with pronounced psychopathology. Psychiatr. Neurol. Med. Psychol. 33, 744-748.

Yoon, S.Y., Jain, U., Shapiro, C., 2012. Sleep in attention-deficit/ hyperactivity disorder in children and adults: past, present, and future. Sleep Med. Rev. 16, 371-388. 